\title{
The IL-2/Anti-IL-2 Complex Attenuates Cardiac Ischaemia-Reperfusion Injury Through Expansion of Regulatory T Cells
}

\author{
Junhui Xiao ${ }^{\mathrm{a}, \mathrm{b}} \quad$ Kunwu Yu ${ }^{\mathrm{a}}$ Ming $\mathrm{Li}^{\mathrm{a}} \quad$ Chuanyin Xiong ${ }^{\mathrm{b}} \quad$ Yuzhen Wei ${ }^{\mathrm{a}}$ \\ Qiutang Zenga \\ anstitute of Cardiology, Union Hospital, Tongji Medical College, Huazhong University of Science and \\ Technology, Wuhan; 'Huadu District People's Hospital, Southern Medical University, Guangzhou, \\ Guangdong, P.R. China
}

\section{Key Words}

Cytokines - Inflammation - Immunotherapy • Ischaemia/reperfusion injury • Regulatory T-lymphocytes (Tregs)

\begin{abstract}
Background/Aims: Regulatory $T$ cells (Tregs) can suppress immunologic damage in myocardial ischaemia/reperfusion injury (MIRI), however, the isolation and ex vivo expansion of these cells for clinical application remains challenging. Here, we investigated whether the IL-2/anti-IL-2 complex (IL-2C), a mediator of Treg expansion, can attenuate MIRI in mice. Methods: Myocardial I/R was surgically induced in male C57BL/6 mice, aged 8-10 weeks, that were randomly assigned to 1) sham group (Sham), 2) Phosphate Buffered Saline (PBS), 3) IL2-anti-IL-2 Ab complex (IL-2C), or 4) sham group, 5) PBS, 6) IL-2C after MIRI, or 7) IL-2C, 8) IL-2C+anti-CD25 mAbs, or 9) IL-2C; 10) IL-2C+anti-TGF- $\beta 1$ mAbs, 11$)$ IL-2C+anti-IL-10 mAbs. The following parameters were measured at different time points: infarct area, myocardial apoptosis, splenocytes, the inhibitory function of Tregs, and presence of inflammatory factors. In addition, immunohistochemistry analysis was performed. Results: We observed that Tregs were activated in response to MIRI. IL-2C administered before MIRI induced Treg expansion in both spleen and heart, attenuated Th1 and Th17 cell numbers, improved myocardial function, and attenuated both infiltration of inflammatory cells and apoptosis after MIRI. Furthermore, IL-2C administration reduced expression of inflammatory cytokines in the heart and attenuated proliferation of splenic cells. Depletion of Tregs with anti-CD25 mAb abrogated the beneficial effects of IL-2C. However, IL-2C-mediated myocardial protection was not dependent on either IL-10 or TGF- $\beta$. In addition, IL-2C administration after MIRI did not reduce infarct area, but did improve myocardial function slightly and reduced myocardial fibrosis. Conclusion: Our results demonstrate that IL-2C-induced Treg expansion attenuates MIRI and improves myocardial recovery in vivo, suggesting that IL- $2 \mathrm{C}$ is a promising therapeutic target for myocardial IRI.
\end{abstract}




\section{Introduction}

Early restoration of blood flow through an occluded coronary artery is the most effective therapy to reduce infarct size and improve clinical outcome after acute myocardial infarction [1]. However, reperfusion after ischaemia itself causes additional complications, including cardiomyocyte death and an increase in infarct size due to a process called myocardial ischaemia/reperfusion (I/R) injury. The pathogenesis of MIRI is multifactorial, with inflammation being a common feature. There are considerable data indicating important roles for various elements of the immune response in MIRI [2].

CD4+ T-cells, a heterogeneous cell population that can be further subdivided into T-helper (Th) Th1, Th2 and Th17 and regulatory T-cells (Tregs) by their function, mediate adaptive immune responses that can be harmful during MIRI. Previous reports have demonstrated that interferon (IFN)- $\gamma$ secreted by Th1 cells and interleukin (IL)-17A secreted by $\gamma \delta$ T-cells and Th17 cells promote progression of MIRI $[3,4]$. Tregs are a subset of T-cells with an immune-modulatory function, commonly identified by expression of CD4 and CD25 on their cell surface and expression of the transcription factor Forkhead box P3 (Foxp3) in the nucleus [5]. They are capable not only of modulating the adaptive immune response by preventing effector T-cell proliferation/function but also of inhibiting the innate immune response $[6,7]$. Tregs convey suppressive action through cell-to-cell contact-mediated inhibition of immune cells and/or secretion of inhibitory factors such as IL-10 and transforming growth factor (TGF)- $\beta 1$ [8]. Previous publications have reported that adoptive transfer of Tregs is beneficial in kidney, brain, liver and myocardial ischaemia/reperfusion (I/R) injury (MIRI) [9-13]. However, adoptive transfer of Tregs requires larger numbers of donors or in vitro stimulation and has proven difficult to translate into the clinical setting.

IL-2 is a cytokine primarily produced by activated T cells and is a potent growth factor for immune cells, including T cells and natural killer (NK) cells [14]. The magnitude and duration of IL-2 effects can be markedly improved by complexing with IL-2 antibodies, and more recently, selective targeting of immune cells has also been achieved [15]. Through injection of low doses of IL-2 complexed with the anti-IL-2 neutralizing monoclonal antibody (mAb) JES6-1, a marked increase in Treg cells was observed in multiple organs, including the liver and gut, as well as spleen and LNs, with a modest increase in Treg cells observed in the thymus. Furthermore, pretreatment with IL-2-anti-IL-2 Ab (IL-2C) rendered mice resistant to induction of EAE and induced tolerance to fully MHC-incompatible pancreatic transplants [16]. In the cardiovascular system, IL-2C inhibits progression of atherosclerosis, angiotensin II-induced aortic stiffening, and remodelling after myocardial infarction [17-19]. However, no studies have evaluated the effects of IL-2C and Tregs on myocardial ischaemia/ reperfusion (I/R) injury, which is important step to clarify the mechanism of Treg effects on MIRI and to identify potential new therapeutic targets for MIRI.

\section{Materials and Methods}

Mice

Male C57BL/6 mice aged 8-10 weeks were purchased from Beijing University (Beijing, China). Mice were maintained on a chow diet in a 12-hour light/12-hour dark environment at $25^{\circ} \mathrm{C}$ in the Tongji Medical School Animal Care Facility, according to institutional guidelines. All experiments were carried out in compliance with the guide lines of the Care and Use of Laboratory Animals (Science and Technology Department of Hubei Province, China).

In vivo myocardial I/R protocol

Surgical induction of myocardial I/R was performed as previously described [20]. Briefly, mice were anaesthetized with ketamine $(50 \mathrm{mg} / \mathrm{kg}$ ) and sodium pentobarbital (50 mg/kg), orally intubated, and connected to a rodent ventilator. A left thoracotomy was performed. The left anterior descending (LAD) coronary artery was visualized and ligated using 8-0 silk suture around fine PE-10 tubing with a slip knot. 
Mice were subjected to 30 minutes of LAD ischaemia followed by varying periods of reperfusion. Shamoperated animals were subjected to the same surgical procedures, except that the suture was passed under the LAD but not tied. Echocardiographic and haemodynamic analyses were performed prior to sacrifice. The infarct area was determined using Evans blue and 2, 3,5-triphenyltetrazolium chloride (TTC) staining. The Evens blue-negative stained portion (ischaemic/reperfused tissue or area at risk [AAR]) was isolated and used for all assays including real-time PCR, Western blotting, and biochemical and immunohistological measurements [21].

\section{Treatment and groups}

C57BL/6 mice were subject to sham treatment or 30 minutes ischaemia followed by 1 hour reperfusion, and all parameters were examined at 4 hours, 1 day, 3 days, 7 days, or 14 days.

To elucidate the role of IL-2C in MIRI, C57BL/6 mice were randomly assigned to 3 groups. 1) sham group (Sham), 2) myocardial I/R group that received PBS (PBS), 3) myocardial I/R group that received IL-2C (IL-2C). IL-2C was mixed with anti-IL-2 (JES6-1) (R\&D Systems) at a 1:5 ratio (1 mg of recombinant murine IL-2 and $5 \mathrm{mg}$ of anti-IL-2), and incubated at $37^{\circ} \mathrm{C}$ for 30 minutes. IL-2C or PBS were intraperitoneally administered to mice for 3 consecutive days, beginning 5 days before MIRI. Both the sham operation group and the PBS group were used for controls. Blood, cardiac tissues, and spleen were harvested at different time points after MIRI.

Next, IL-2C was administered for 3 consecutive days, beginning 1 day after MIRI in order to investigate the effect of IL-2C on reperfusion. Infarct area, cardiac function and histological analyses were performed on days 1,5 and 14 .

To investigate the mechanism of IL-2C's effect on MIRI, C57BL/6 mice were randomly assigned to one of two groups: 1) IL-2C group (IL-2C) or 2) IL-2C group receiving PC61, an anti-CD25 antibody (IL-2C/ PC61). To investigate the mechanism of Treg function in MIRI, C57BL/6 mice were randomly assigned to one of three groups: 1) IL-2C group (IL-2C); 2) IL-2C group receiving anti-TGF- $\beta 1$ antibodies (IL-2C+antiTGF- $\beta 1$ ); or 3) IL-2C group received anti-IL-10 antibodies (IL-2C+anti-IL-10).

To deplete Tregs, anti-CD25 the PC61 antibody (Bio-XCell, West Lebanon, NH) was administered to mice at a dose of $0.3 \mathrm{mg} / \mathrm{mouse}$ for 2 consecutive days, beginning 1 day before MIRI. Depletion of Foxp3+CD4+ cells was confirmed by flow cytometry analysis of the spleen. In the TGF- $\beta$-blocking experiments, $150 \mathrm{mg}$ of anti-TGF- $\beta$ antibody (AB-100-NA; R\&D Systems, Minneapolis, MN) or anti-IL-10 antibody or rabbit IgG isotype control antibody (eBioscience, San Diego, CA) was intraperitoneally administered to mice on day 24 and day 0 before MIRI.

\section{Echocardiographic and heamodynamic analysis of cardiac function}

A Vevo 2100 high-resolution microimaging system with a $30 \mathrm{MHz}$ transducer was used (Visualsonic, Toronto, Ontario, Canada). Mice were anaesthetized with 1.5\% isoflurane and two-dimensional echocardiographic views of the mid-ventricular short axis and parasternal long axes were obtained. Left ventricular (LV) fractional shortening (FS) and LV ejection fraction (EF) were calculated from digital images using a standard formula as previously described [22,23]. Echocardiographic acquisition and analysis were performed by a technician who was blinded to treatment groups.

For haemodynamic performance measurements, a 1.4 French micromanometer-tipped catheter (SPR671, Millar Instruments, Houston, TX) was inserted into the right carotid artery and then advanced into the LV. LV end-diastolic pressure (LVEDP) was measured, and maximal (LV +dp/dtmax.) and minimal (LV -dp/ dtmin.) first derivative of LV pressure rise and fall were calculated.

\section{Infarct area assessment}

Infarct size after I/R injury was determined as previously described [24]. Briefly, at the end of a 4-hour reperfusion period, mice were anaesthetized, the LAD was re-occluded at the previous ligation, and $1 \mathrm{ml}$ of 2.0\% Evans blue (Sigma-Aldrich, St. Louis, MO) was injected. The heart was quickly excised, immediately frozen, and sliced. Sections were then incubated in a 1\% 2, 3,5-triphenyltetrazolium chloride (TTC, Sigma-Aldrich, St. Louis, MO) solution and digitally photographed. Left ventricular area, area at risk (AAR) and infarct area were determined by computerized planimetry using Image-Pro Plus software (Media Cybernetics Inc., Bethesda, Maryland).

\section{KARGER}


Serum troponin $T$

Blood concentrations of troponin T were measured as an index of cardiac cellular damage using the quantitative rapid assay kit (Roche Diagnostics GmbH, Mannheim, Germany) as previously described [25, 26].

\section{Myocardial apoptosis}

For terminal deoxynucleotidyl-transferase mediated dUTP nick-end labelling (TUNEL) staining, hearts were fixed in $4 \%$ paraformaldehyde, embedded in paraffin, cut into 4-5- $\mu \mathrm{m}$ thickness sections and treated according to manufacturer's instructions using the In Situ Cell Death Detection kit (Roche Diagnostics $\mathrm{GmbH}$, Mannheim, Germany). Following this, sections were co-stained with anti-sarcomeric actin antibody (Sigma-Aldrich, St. Louis, MO) to specifically mark cardiomyocytes. TRITC goat anti-mouse antibody was used as secondary antibody. Total nuclei were stained with DAPI. More than 5 fields in $>3$ different sections/ animal were examined.

Cardiac caspase-3 activity was measured as previously described [27] using a caspase colorimetric assay kit following the manufacturer's instructions (Chemicon, Temecula, CA). Absorbance of p-nitroaniline cleaved by caspase was measured at $405 \mathrm{~nm}$ using a microplate reader (ELx800, Bio-Tek Instruments, USA). The results were standardized to the sham group for comparison of fold change in caspase- 3 activity.

\section{Flow Cytometry}

The heart-draining lymph nodes were harvested from sham mice and myocardial I/R mice at different time points. After administration of PBS, IL2C or PC/61, splenic monocytes were isolated from mice. FicollPaque Plus and RCLB were used to remove the erythrocytes. The $\mathrm{CD} 45^{+} \mathrm{CD}^{+} \mathrm{CD}^{+} \mathrm{T}$ cells were stained with anti-CD45, antiCD3 and anti-CD4 Abs and NKT cells with anti-CD3 and antiNK1.1 Abs. Th1 and Th17 cells were stained with anti-CD4 Ab, followed by staining with antiIFN- $\gamma$ or IL-17A $\mathrm{Ab}$ after fixation and permeabilization according to the manufacturer's instructions. The $\mathrm{CD}^{+}{ }^{+} \mathrm{CD} 25^{+}{ }^{+}$oxp $3{ }^{+}$Tregs were stained with anti-CD4-FITC and anti-CD25-PE Abs, followed by staining with anti-Foxp3-APC Ab after fixation and permeabilization according to the manufacturer's instructions. To characterize splenic DCs, cells were stained with CD11c, CD86, and MHC-II $\mathrm{Ab}$ for $30 \mathrm{~min}$. Flow cytometry was performed using a FACSCalibur (BD Immunocytometry Systems, USA) and all analyses, including MFI (mean fluorescence intensity), were performed using FlowJo software (Treestar Inc., OR, USA).
Table 1. Primer sequences of TGF- $\beta$, IL-12p40, GAPDH, IL-10, IFN- $\gamma$, Bcl-2, Bax, TNF- $\alpha$, IL-13, IL-17a, Arginase I, CD206 for RT-PCR were shown, all these primers were synthesized by Invitrogen in Shanghai

\begin{tabular}{ll}
\hline Molecule & sequence(5'-3') \\
\hline TGF- $\beta 1$ sense & CAGTGGCTGAACCAAGGAGAC \\
TGF- $\beta 1$ anti-sense & ATCCCGTTGATTTCCACGTG \\
IL-12p40 sense & ATCGTTTTGCTGGTGTCTCC \\
IL-12p40 anti-sense & CTTTGTGGCAGGTGTACTGG \\
GAPDH sense & TGCAGTGGCAAAGTGGAGATT \\
GAPDH anti-sense & TTGAATTTGCCGTGAGTGGA \\
IL-10 sense & ATGCTGCCTGCTCTTACTGACTG \\
IL-10 anti-sense & CCCAAGTAACCCTTAAAGTCCTGC \\
IFN- $\gamma$ sense & AGAGCCAGATTATCTCTTTCTACCTCAG \\
IFN- $\gamma$ anti-sense & CCTTTTTCGCCTTGCTGTTG \\
Bcl-2 sense & GTACCTGAACCGGCATCTG \\
Bcl-2 anti-sense & GCTGAGCAGGGTCTTCAGAG \\
Bax sense & TGCAGAGGATGATTGCTGAC \\
Bax anti-sense & GATCAGCTCGGGCACTTTAG \\
TNF- $\alpha$ sense & TCAATCGGCCCGACTATCTC \\
TNF- $\alpha$ anti-sense & CAGGGCAATTGATCCCAAAGT \\
IL-13 sense & CACACAAGACCAGACTCCCCTG \\
IL-13 anti-sense & GGTTACAGAGGCCATGCAATATCC \\
IL-17a sense & TGTGAAGGTCAACCTCAAAGTCT \\
IL-17a anti-sense & GAGGGATATCTATCAGGGTCTTCAT \\
Arginase I sense & GGAATCTGCATGGGCAACCTGTGT \\
Arginase I anti-sense & AGGGTCTACGTCTCGCAAGCCA \\
CD206 sense & GAGGGAAGCGAGAGATTATGGA \\
CD206 anti-sense & GCCTGATGCCAGGTTAAAGCA \\
\hline & \\
\hline
\end{tabular}




\section{Cellular Physiology Cell Physiol Biochem 2017;44:1810-1827 \begin{tabular}{l|l} 
and Biochemistry DOI: 10.1159/000485818 & $\begin{array}{l}\text { (c) } 2017 \text { The Author(s). Published by S. Karger AG, Basel } \\
\text { www.karger.com/cpb }\end{array}$
\end{tabular} \\ Xiao et al.: IL-2/Anti-IL-2 mAb and MIRI}

\section{Cell Proliferation}

To assess effects on cell proliferation, splenocytes were isolated using Ficoll-Paque (GE Healthcare) and cultured at $2 \times 10^{5}$ cells/well in flat-bottomed 96-well plates and stimulated with purified soluble antiCD3 antibody $\left(1 \mathrm{~g} / \mathrm{ml}, \mathrm{R} \& \mathrm{D}\right.$ Systems) at $37^{\circ} \mathrm{C}$ in $5 \% \mathrm{CO} 2$ for $72 \mathrm{~h}$. The cells were pulsed with $1 \mathrm{Ci}$ of [3H] thymidine for the last 16 hours and harvested with an automatic cell harvester (Pharmacia). Thymidine incorporation was assessed using a liquid scintillation counter (LKB Wallac, Perkin Elmer).

\section{Tregs and T-Effector Cell Co-Culture}

$\mathrm{CD} 4^{+} \mathrm{CD} 25^{+}$and $\mathrm{CD} 4^{+} \mathrm{CD} 25^{-} \mathrm{T}$-cells were isolated from the spleens of mice 36 hours after receiving 3 doses of IL-2/anti-IL-2 mAb complex or vehicle using a mouse $\mathrm{CD} 4^{+} \mathrm{CD} 25^{+}$regulatory $\mathrm{T}$ cell isolation kit from Miltenyi Biotec. Subsequently, cells were cultured with responder T-cells (Tresps: CD4+CD25- T-cells) $\left(2 \times 10^{4}\right.$ cells/well) at ratios of 1:1, 1:2 or 1:4 in media containing $2 \mu \mathrm{g} / \mathrm{ml}$ anti-CD3 and $2 \mu \mathrm{g} / \mathrm{ml}$ anti-CD28 Abs in the presence of irradiated APCs $\left(5 \times 10^{3}\right.$ cells/well). After $\left.72 \mathrm{~h},{ }^{3} \mathrm{H}\right]$ thymidine $(1 \mu \mathrm{Ci} /$ well $)$ was added, and cells were incubated for $16 \mathrm{~h}$, followed by scintillation counting (beta counter) to assess proliferation. The percent of proliferation inhibition was determined using the following formula: 1-(median $\left.{ }^{3} \mathrm{H}\right]$ thymidine uptake of 1:1 CD4+CD25+: $\mathrm{CD}^{+} \mathrm{CD} 25^{-}$co-culture/median [ $\left.{ }^{3} \mathrm{H}\right]$ thymidine uptake of $\mathrm{CD} 4^{+} \mathrm{CD} 25^{-}$cells).

\section{Real-time PCR}

Total RNA was extracted from cultured cells or tissues using Trizol (Invitrogen, Carlsbad, CA) and reverse transcribed into cDNA using the PrimeScript RT reagent kit (Takara Biotechnology, Dalian, China) according to the manufacturer's instructions. mRNA levels of target genes were quantified using SYBR Green Master Mix (Takara Biotechnology, Dalian, China) with ABI PRISM 7900 Sequence Detector system (Applied Biosystems, Foster City, CA). Each reaction was performed in duplicate, and changes in relative gene expression were normalized to GAPDH levels using the relative threshold cycle method (Table 1).

\section{Immunohistochemistry and Masson staining}

For the detection of inflammatory cells, one cryosection from each of blocks A, B and D of 3-, 7- and 14-day samples were stained with anti-myeloperoxidase (MPO, Abbiotec, UK), anti-Mac-2 (AbDSerotec, UK), anti-CD45 (eBioscience, USA), anti-CD31, anti-PNCA, and anti-Foxp3 (eBioscience, USA) overnight at $4^{\circ} \mathrm{C}$, followed by respective secondary HRP-conjugated antibodies for $1 \mathrm{~h}$ at room temperature. Positive cells were visualized with $\mathrm{DAB}$, and nuclei were counterstained with haematoxylin. Five fields $(200$ magnification) in both the PIZ and NIZ on each cryosection from three blocks per heart were analysed and averaged. Furthermore, fibrous areas were stained with Masson trichrome.

\section{Statistical Analysis}

The results are expressed as the mean \pm SD unless otherwise indicated. Comparisons between two groups were performed using Student's t test. One-way ANOVA was used for multiple comparisons between $\geq 3$ groups, followed by the Holm-Sidak test. GraphPad Prism 6.0 was used for the statistical analysis. The significance level was set at $\mathrm{p}<0.05$.

\section{Results}

\section{Treg Cells Become Activated in Response to MIRI}

To test for Treg activation after MIRI, we analysed the heart-draining lymph nodes. Here, increased frequencies of Treg cells were found in mLNs on days 3, 7, and 14 post-MI compared with sham-operated animals analysed on day 7 after surgery (Fig. 1A). Absolute numbers of Treg cells were also increased, peaking on day 7. In addition to heart-draining lymph nodes, we evaluated Treg cell infiltration into the healing infarct. Compared with sham-operated mice, the numbers of Treg cells were increased in the infarct border on days 3 and 7 post-MI and post-MIRI (Fig. 1B).

Expansion of $C D 4^{+} C D 25^{+}$Foxp $3^{+}$Regulatory Cells in Spleen and Heart Using IL-2/Anti-IL-2 mAb Complex Treatment

First, we measured Tregs after MIRI. We administered IL-2C or PBS for 3 consecutive days beginning 5 days before MIRI because a previous study showed that Treg expansion reaches a 


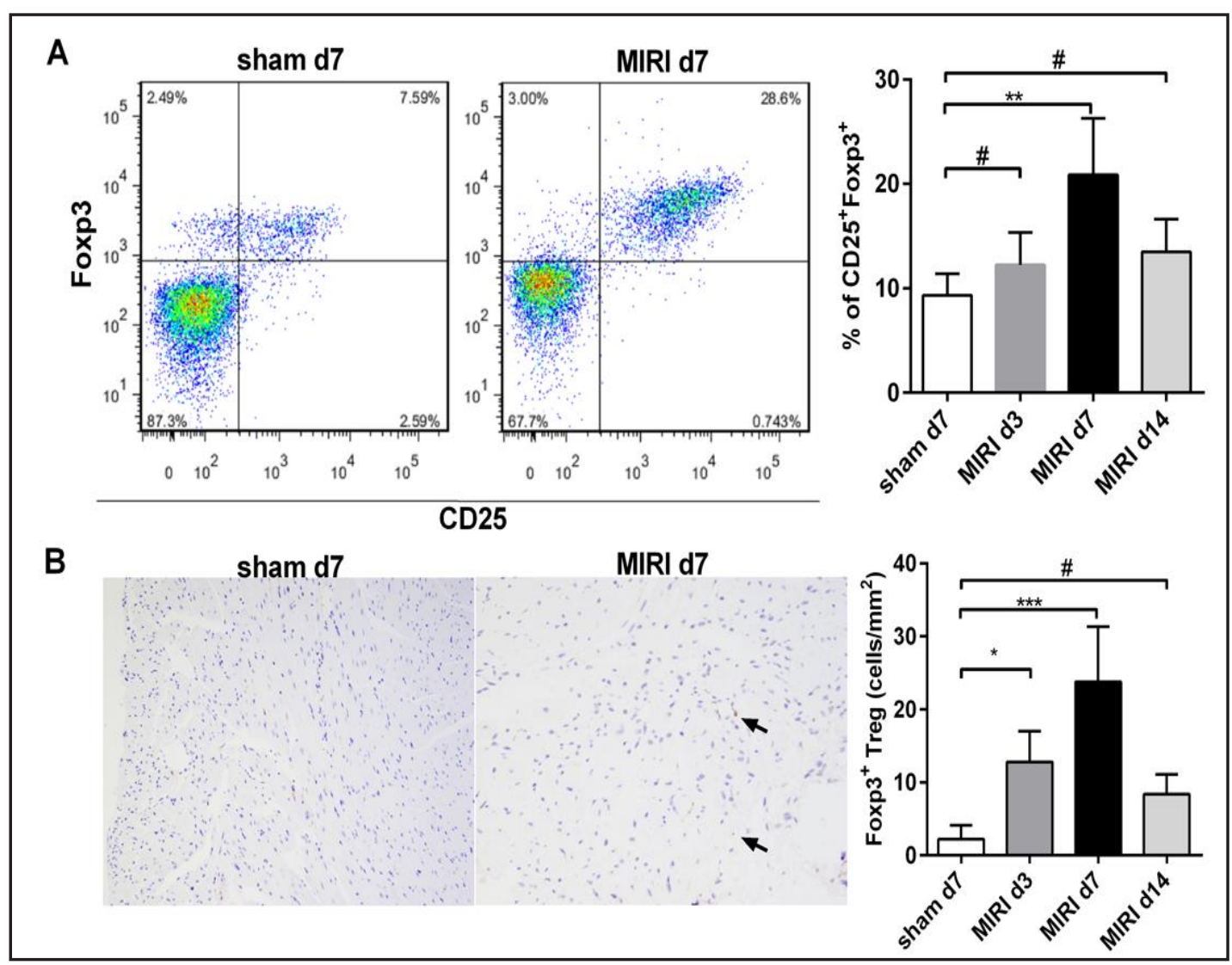

Fig. 1. Foxp3+CD4+ regulatory $\mathrm{T}$ cell (Treg cell) activation in heart-draining lymph nodes and infiltration into the infarct zone. A. Representative images showing CD25 and Foxp3 expression on CD4+ T cells from sham-operated and infarcted mice $7 \mathrm{~d}$ post-I/R, and kinetics of Treg cell expansion in heart-draining lymph nodes of sham-operated and MIRI mice analysed at different time points ( $n=3-5$ per group). B. Immunohistochemistry staining of Foxp3+ cells (arrow head) and kinetics of Treg cell numbers in the infarct border zone of sham-operated and MIRI mice analysed at different time points ( $\mathrm{n}=3-8$ per group). ${ }^{\#} \mathrm{P}>0.05,{ }^{*} \mathrm{P}<0.05,{ }^{* *} \mathrm{P}<0.01$, and ${ }^{* * *} \mathrm{P}<0.001$.

peak five days after IL-2C treatment [16]. IL-2C induced significant expansion of Foxp3+CD4+ Tregs in both spleen and heart on day 5 (Fig. 2A and B). In comparison with normal animals, the size of the spleen was significantly increased (Fig. 2A). Immunohistochemistry staining demonstrated that in cardiac tissues Tregs were elevated 5-fold (Fig. 2B), indicating that the IL-2/Anti-IL-2 mAb complex expands Tregs in a MIRI model.

\section{IL-2/Anti-IL-2 mAb Complex Treatment Ameliorates MIRI}

The extent of injury and heart dysfunction were assayed 4 hours and 1 day after initiation of reperfusion. With similar AAR, the infarct size/AAR was significantly smaller in IL-2Ctreated mice than in wild-type mice (Fig. 3A). In parallel, we observed improved cardiac function, indicated by elevated EF and FS, in IL-2C mice after myocardial I/R compared with wild-type mice. Less serious injury was also apparent from lower levels of serum cTnT being observed in IL-2C mice (Fig. 3B). These results suggest that IL-2C is protective against myocardial I/R injury.

\section{IL-2/Anti-IL-2 mAb Complex Treatment affected the percentage of different monocytes}

We next analysed splenocytes using FACS and investigated whether IL-2C protection was dependent changes in immune cells other than Tregs in the spleen. First, we found that the percentage and number of $\mathrm{CD}^{+}{ }^{+} \mathrm{T}$-cells was increased significantly 2 days after the end of 


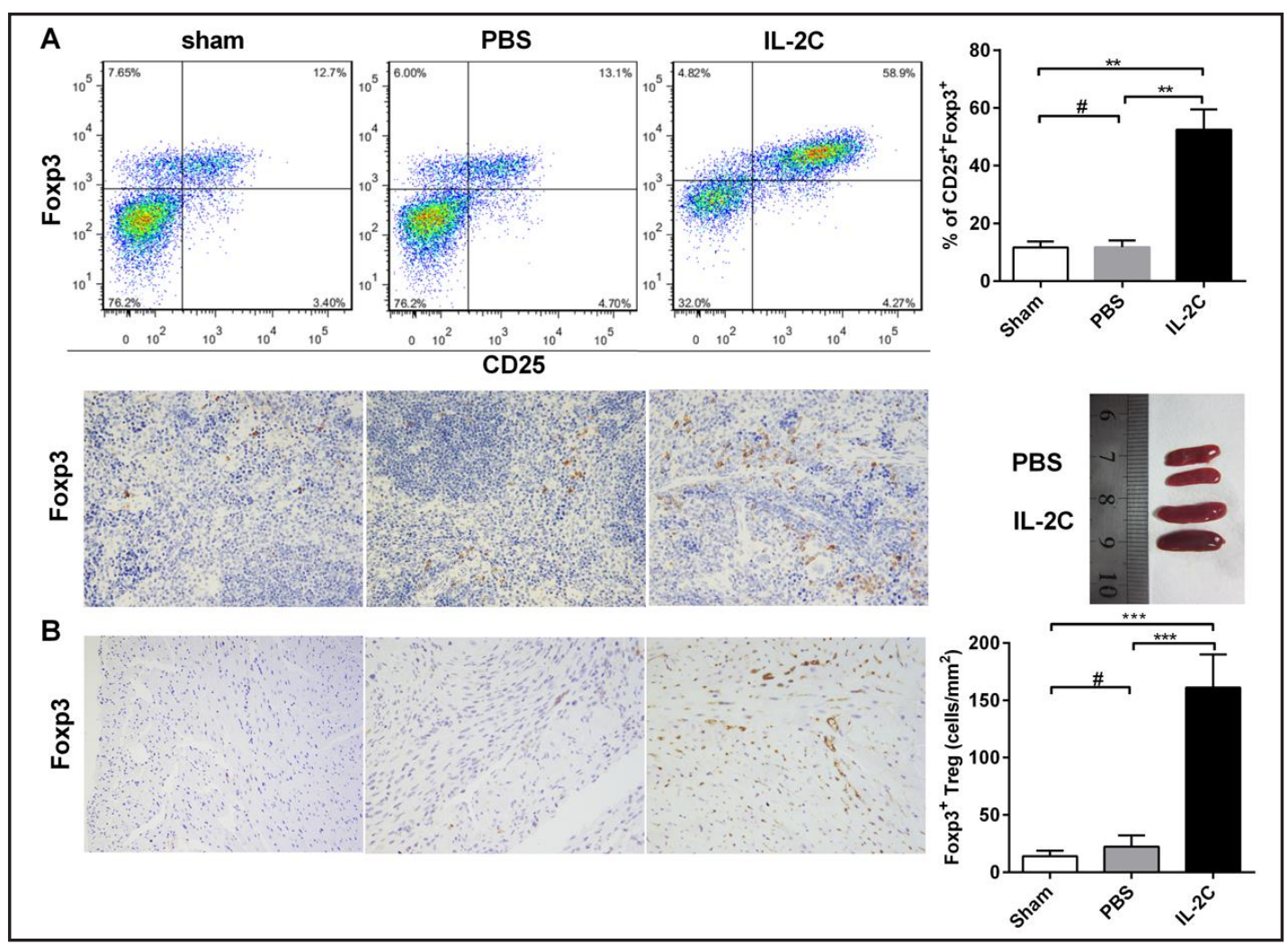

Fig. 2. Expansion of Tregs in both spleen and kidney after MIRI by IL-2C treatment. IL-2C treatment significantly increased the proportion of Foxp3+CD4+ Tregs among CD4+ T cells in both spleen (A and B) and heart (A and E) compared with the PBS control. ${ }^{*} \mathrm{P}>0.05,{ }^{*} \mathrm{P}<0.05,{ }^{* *} \mathrm{P}<0.01$, and ${ }^{* * *} \mathrm{P}<0.001$.

treatment. In contrast, IL-2C injection inhibited pro-inflammatory Th1 and Th17 cells. This observation is in agreement with recent reports that provided evidence of crosstalk between Tregs, DCs, and NKT cells $[28,29]$ and identified a role for NKT cells in oral tolerance [30]. Surprisingly, IL-2C injection promoted NKT cells. However, this treatment did not affect the phenotype of dendritic cells with respect to CD86 and MHC-II expression (Fig. 4).

\section{IL-2C Attenuates Cardiomyocyte Apoptosis after I/R in vivo}

Apoptosis contributes significantly to myocardial I/R injury [31]. We hypothesized that the role of IL-2C in myocardial I/R is associated with its effects on cardiomyocyte apoptosis. To test this hypothesis, we carried out terminal deoxynucleotidyl-transferase mediated dUTP nick-end labelling (TUNEL) staining of LV sections from different experimental groups $4 \mathrm{~h}$ after myocardial I/R. As shown in Fig. 5A and B, IL-2C treatment significantly decreased the number of TUNEL-positive cardiomyocytes compared to control, suggesting that IL-2C treatment inhibits the extent of cardiomyocyte apoptosis induced by Tregs. Concomitantly, caspase 3 activity in ischaemic myocardium was also down-regulated by IL-2C treatment (Fig. 5C).

To understand the mechanisms through which IL-2C inhibits cardiomyocyte apoptosis, we examined expression of the Bcl-2 family by real-time polymerase chain reaction. Administration of IL-2C in vivo resulted in a decreased Bax/Bcl-2 ratio after myocardial I/R (Fig. 5D).

\section{IL-2C Reduces Cardiac Immune Cells and Fibrosis}

Previous studies using IL-2C to elevate Tregs demonstrated suppressed infiltration of inflammatory cells in atherosclerotic lesions and cardiac tissue $[17,19]$. Here, we found that total $\mathrm{CD} 45^{+}$leukocytes were significantly decreased in heart by IL-2C treatment. 
A
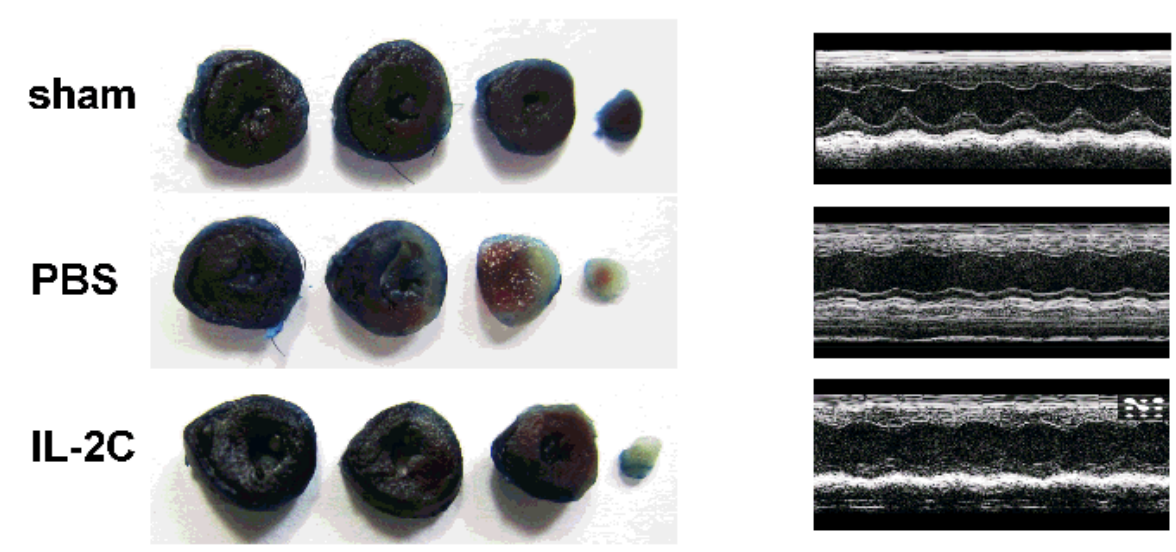

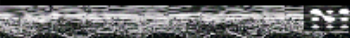

(1)

tes
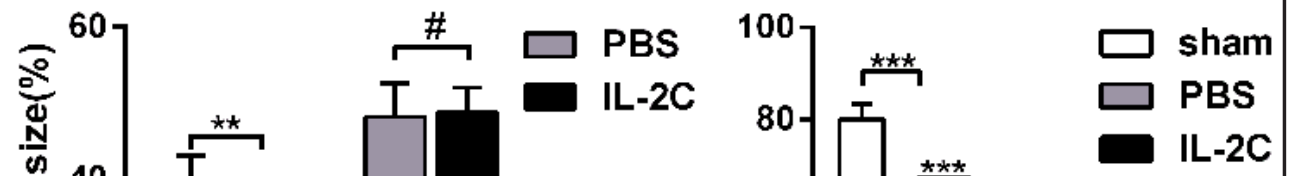

迹

1
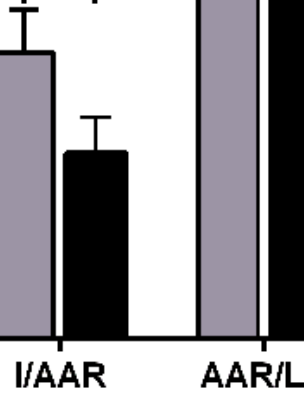

(1)

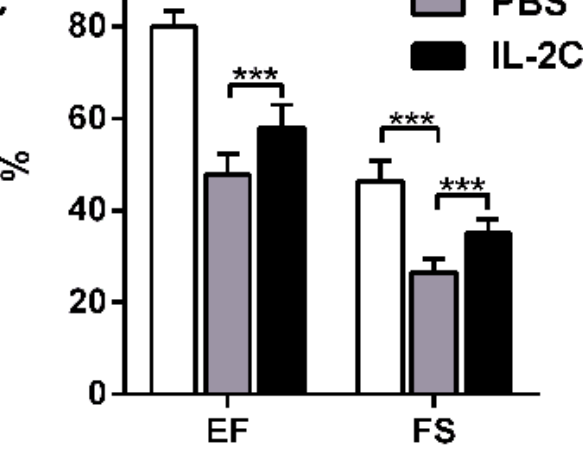

B

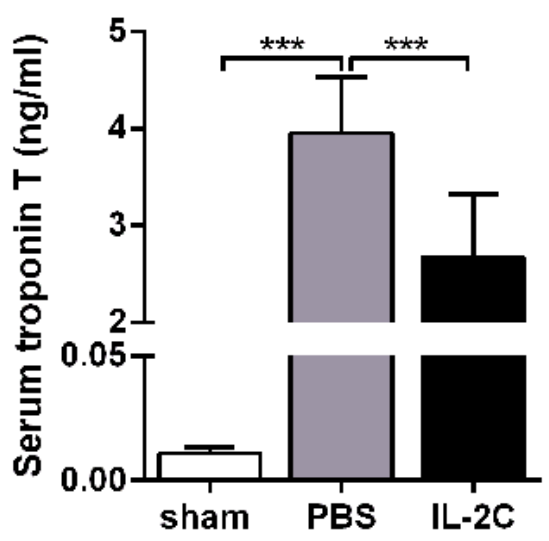

Fig. 3. IL-2C treatment ameliorates myocardial I/R injury. A. Representative images of LV slices and quantification of myocardium infarct size in sham, PBS and IL-2C mice 4 hours after I/R are shown. Representative M-mode images of LV and ejection fraction and LV fractional shortening from sham, PBS and IL-2C mice 1 day after I/R are shown. B. Serum cTnT from sham, PBS and IL-2C mice was measured 1 day after I/R. Data are shown as the mean $\pm \mathrm{SD}$ of 3 to 6 independent experiments. ${ }^{*} \mathrm{P}>0.05,{ }^{*} \mathrm{P}<0.05,{ }^{* *} \mathrm{P}<0.01,{ }^{* * *} \mathrm{P}<0.001$, and ${ }^{* * * *} \mathrm{P}<0.0001$.

Neutrophils and macrophages are the predominant infiltrates during the injury phase of renal IRI, and IL-2C significantly reduced infiltration of these cells in response to MIRI. In addition, myocyte proliferation significantly increased by day 7 following MIRI, and their

\section{KARGER}




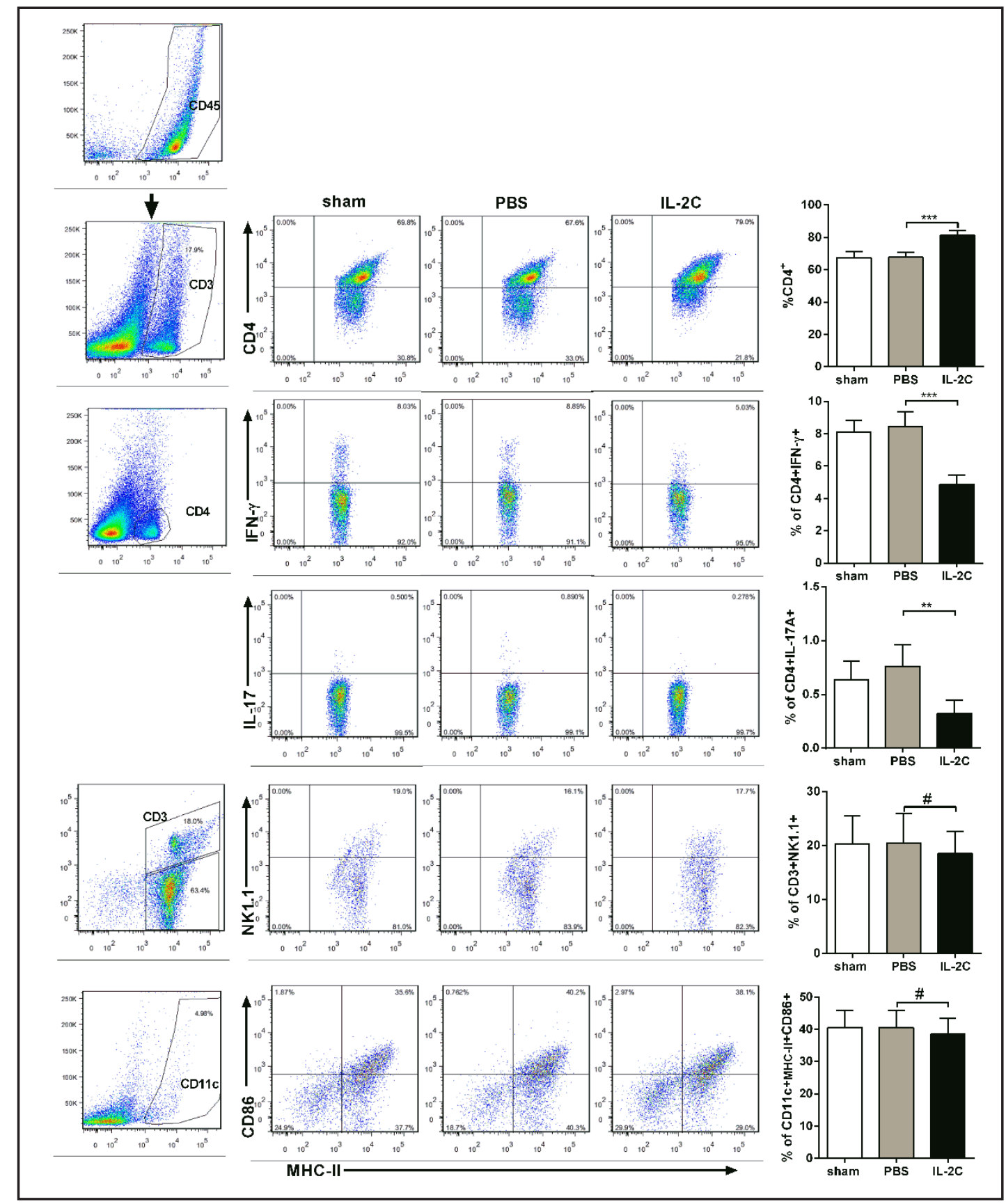

Fig. 4. IL-2/Anti-IL-2 mAb complex treatment affected the differentiation of T cells but not DCs. Representative images of $\mathrm{CD} 4^{+} \mathrm{T}$ cells, $\mathrm{CD} 4^{+} \mathrm{INF}-\gamma^{+} \mathrm{Th} 1, \mathrm{CD} 4^{+} \mathrm{IL}_{-}-17 \mathrm{~A}^{+} \mathrm{Th} 17, \mathrm{CD}^{+} \mathrm{NK} 1.1^{+} \mathrm{NKT}$, and CD11c $\mathrm{MHC}^{+} \mathrm{II}^{+} \mathrm{CD} 86^{+}$ DCs in the spleen are shown. Numbers in the upper right quadrants indicate the percentages of these cells. In addition, the results from the statistical analysis of the average percentages of these cells in spleen of different experimental groups are shown. Approximately 5 to 7 mice were analysed for each group. The values are presented as the mean $\pm \mathrm{SD}$. ${ }^{\#} \mathrm{P}>0.05,{ }^{*} \mathrm{P}<0.05$, ${ }^{* *} \mathrm{P}<0.01,{ }^{* * *} \mathrm{P}<0.001$, and ${ }^{* * * *} \mathrm{P}<0.0001$

proliferation was unaffected by IL-2C. Furthermore, cardiac fibrosis was also significantly decreased in response to MIRI on day 28 following IL-2C treatment, and microvessel density was increased in the IL-2C-treated group compared with the PBS-treated group (Fig. 6). 


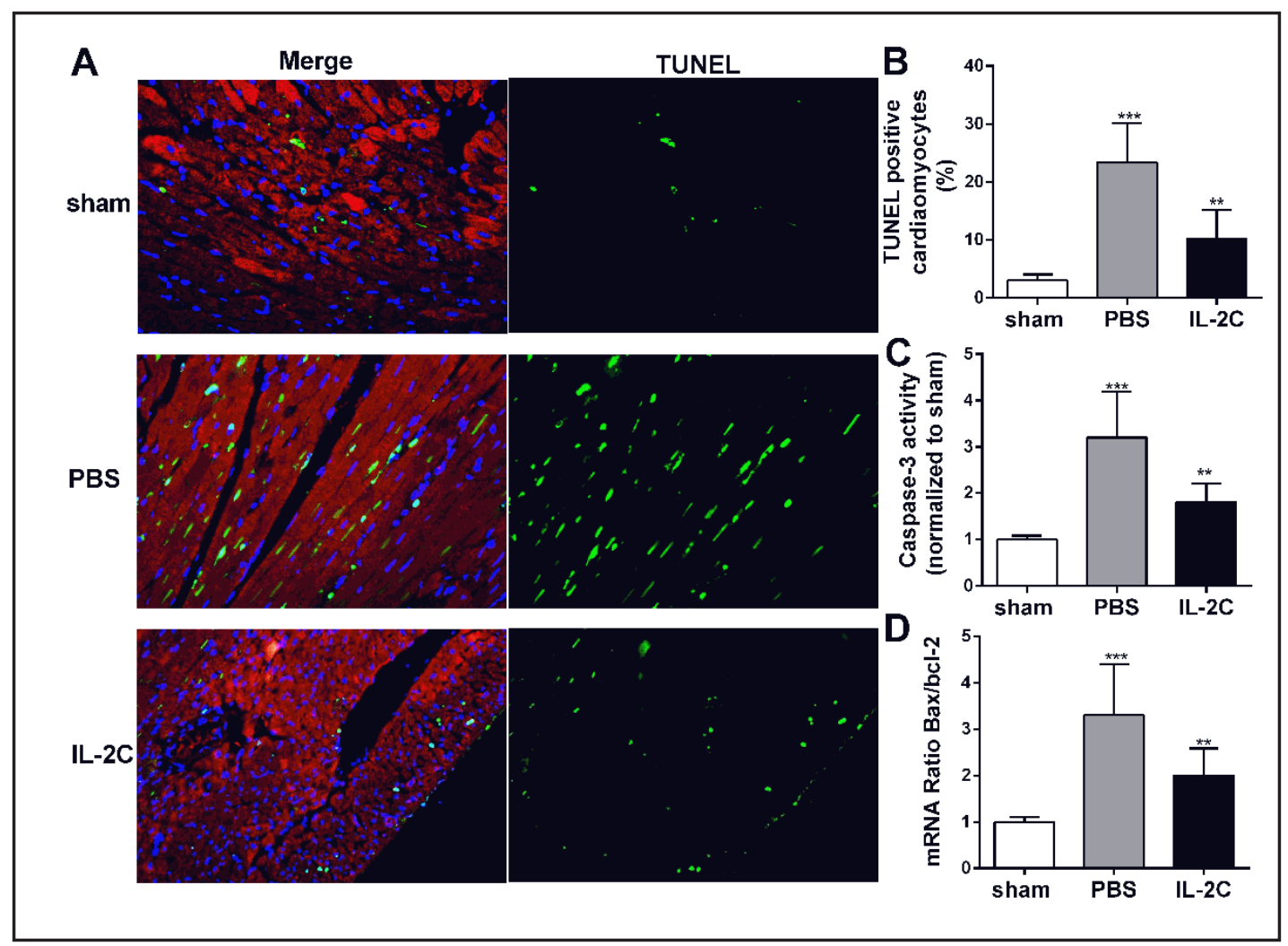

Fig. 5. IL-2C attenuates cardiomyocyte apoptosis after I/R in vivo. A. Representative images of terminal deoxynucleotidyl-transferase mediated dUTP nick-end labelling (TUNEL)-stained heart sections from different groups $4 \mathrm{~h}$ after reperfusion. Apoptotic nuclei were identified by TUNEL staining (green), cardiomyocyte by anti-sarcomeric actin antibody (red), and total nuclei by 4,6-diamidino-2-phenylindole staining (blue). Arrowheads indicate apoptotic cardiomyocytes. Scale bar: $50 \mathrm{~mm}$. B. Percentages of TUNELpositive nuclei over total number of nuclei ( $n=4$ to 5 ). C. Caspase 3 activity in myocardium was assessed after $3 \mathrm{~h}$ of reperfusion, and values were normalized to sham $(n=5)$. D. Real-time polymerase chain reaction (PCR) determined mouse neonatal cardiomyocyte Bcl-2 and Bax messenger ribonucleic acid (mRNA) levels. Results are expressed as Bax/Bcl-2 ratio. Values are presented as mean $\pm \mathrm{SD}$. ${ }^{\#} \mathrm{P}>0.05,{ }^{*} \mathrm{P}<0.05,{ }^{* *} \mathrm{P}<0.01$, $* * * \mathrm{P}<0.001$, and $* * * * \mathrm{P}<0.0001$.

\section{IL-2/Anti-IL-2 mAb Complexes Attenuate Splenocyte Proliferation and Cardiac Pro-} inflammatory Mediators

To determine whether induction of Tregs by IL-2/anti-IL-2 mAb complex affected the proliferative ability of splenocytes, we examined their proliferation in response to anti-CD3 antibodies. After culturing splenocytes for 3 days with anti-CD3 antibodies, proliferation in the IL-2/anti-IL-2 mAb complex-treated mice was attenuated up to $36 \%$ compared with control mice (Fig. 7A). In addition, Treg expansion using the IL-2/anti-IL-2 mAb complex effectively attenuated $\mathrm{CD} 4^{+} \mathrm{T}$ cell proliferation in vitro compared with control mice (Fig. 7B).

We further investigated changes in local inflammatory cytokines after Treg expansion and found that pro-inflammatory cytokines TNF- $\alpha$, IFN- $\gamma$, IL-12, and IL-17A mRNA were down-regulated on day 7 after IR. However, anti-inflammatory cytokines TGF- $\beta 1$ and IL-10 and M2-induced IL-13, Arginase 1, and CD206 were all up-regulated by IL-2C compared to control mice (Fig. 8).

Treg Depletion, but Not TGF- $\beta 1$ and IL-10 Neutralization, Results in Impaired Remodelling

Here, we investigated whether depletion of Tregs altered the effects of IL-2C. When anti-CD25 antibody (PC61) was administered shortly after injection of IL-2C, expansion of 


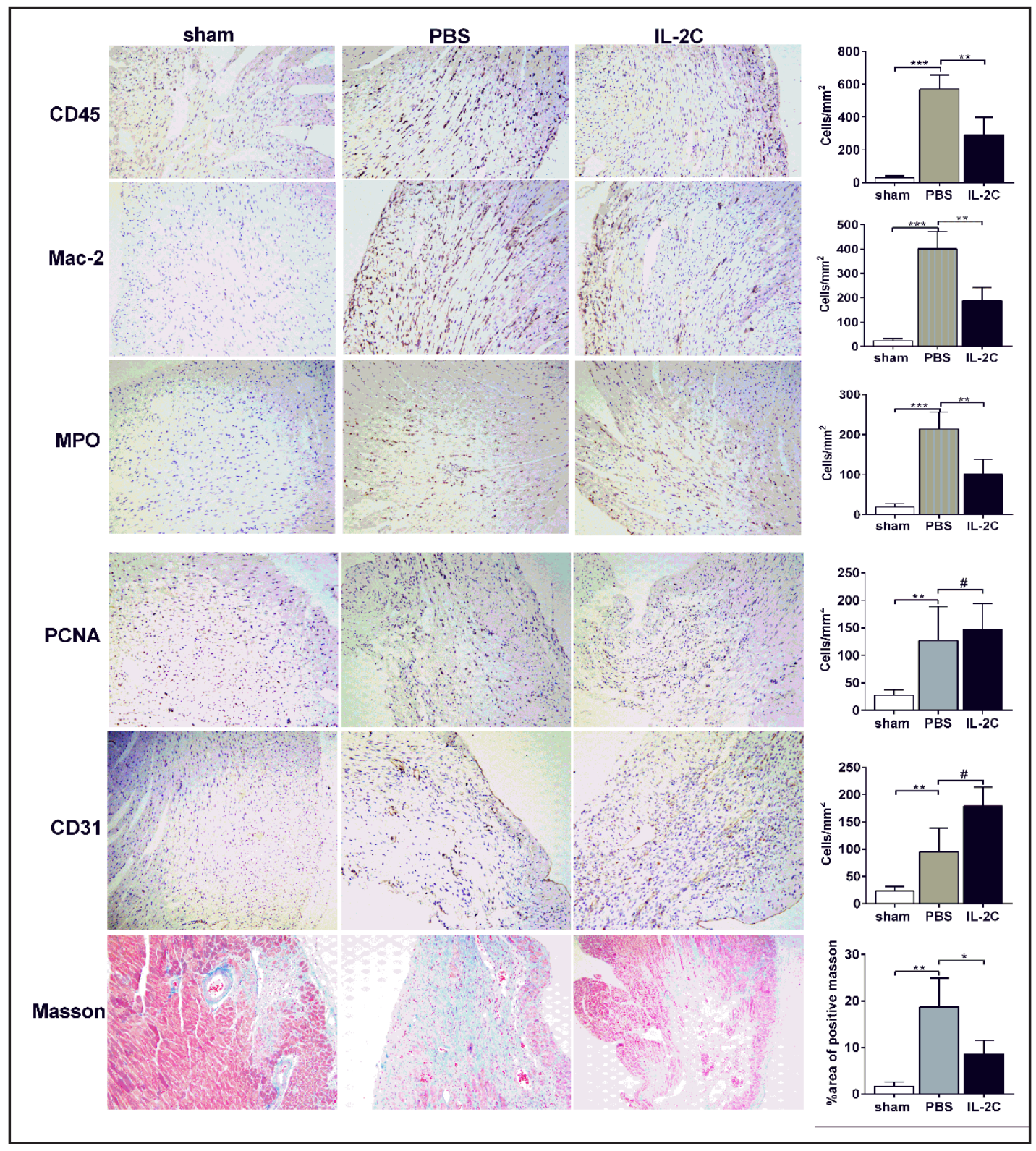

Fig. 6. IL-2C treatment attenuates infiltration of inflammatory cells and fibrosis after MIRI . CD45+ leukocytes, Mac-2+ macrophages, MPO+ neutrophils, PNCA+ proliferating cells, CD31+ microvessel, and Masson staining were performed in cardiac tissue. PCNA, proliferating cell nuclear antigen. Original magnification, $\times 200$ in A, B, D, and E; $\times 40$ in C. Data represent at least 3 independent experiments. ${ }^{\#} P>0.05$, ${ }^{*} \mathrm{P}<0.05,{ }^{* *} \mathrm{P}<0.01$, and ${ }^{* * *} \mathrm{P}<0.001$.

Tregs in the spleen was completely abrogated (Fig. 9A). In addition, infarct size/AAR was significantly larger in IL-2C/PC61 than the IL-2C group (Fig. 9B). In parallel, we observed depressed cardiac function, as indicated by elevated EF, in IL-2C/PC61 mice after myocardial I/R compared with IL-2C alone (Fig. 9C).

To assess the role of IL-10 or TGF- $\beta 1$ in IL-2C-mediated cardiac protection from MIRI, we administered anti-IL-10R mAb or anti-TGF- $\beta 1 \mathrm{mAb}$ after IL-2C treatment. We found that neutralizing anti-IL-10R or anti-TGF- $\beta$ treatment did not abrogate the beneficial effects of IL-2C (Fig. 10). 


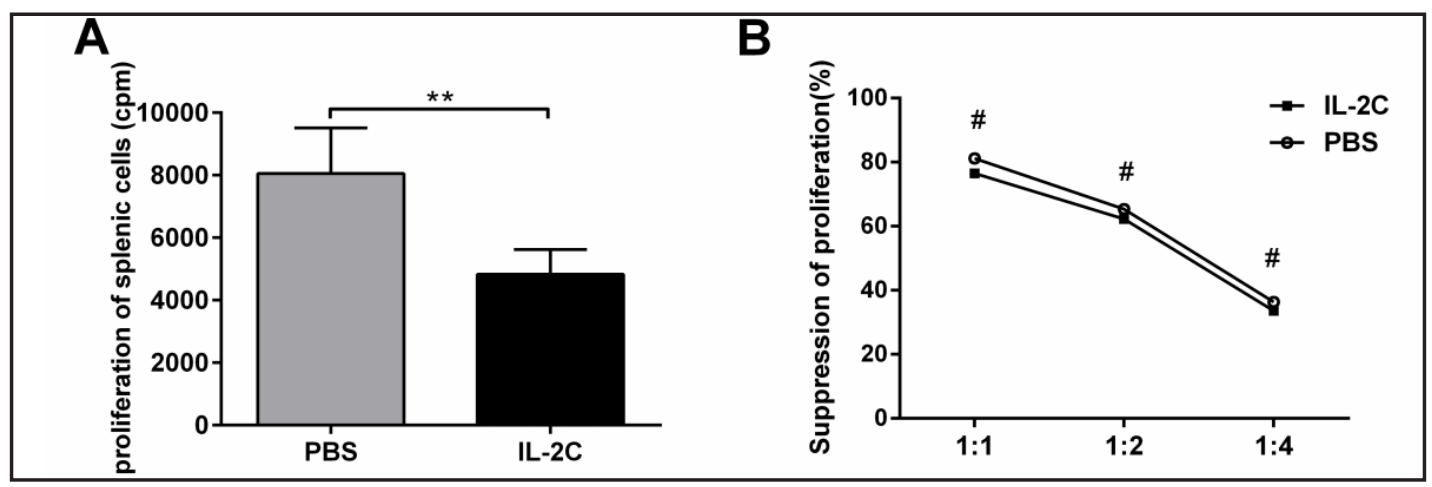

Fig. 7. IL-2C attenuates splenocyte proliferation. A. Average percentages of splenocyte proliferation of different groups was determined using $\left[{ }^{3} \mathrm{H}\right]$ thymidine are shown. B. Dose-dependent suppression of stimulated spleen CD4+ T cell proliferation by Tregs isolated from mice treated with IL-2Cs or PBD; ratios represent Tregs:CD 4+ T cells. The values are presented as the mean $\pm \mathrm{SD} .{ }^{*} \mathrm{P}>0.05,{ }^{*} \mathrm{P}<0.05,{ }^{* *} \mathrm{P}<0.01,{ }^{* * *} \mathrm{P}<0.001$, and $* * * * \mathrm{P}<0.0001$.

IL-2/Anti-IL-2 mAb

Complex Treatment after MIRI Improves Myocardial Fibrosis and Cardiac Function, but Not Infarct Area

To investigate the effects of IL-2C after the onset of reperfusion, IL2C was administered for 3 consecutive days beginning 1 day after MIRI. We found that IL-2C administration after MIRI also induced significant expansion of Foxp3+CD4+ Tregs in both spleen and heart on day 5 (data not shown). However, the infarct size/AAR was not comparable between

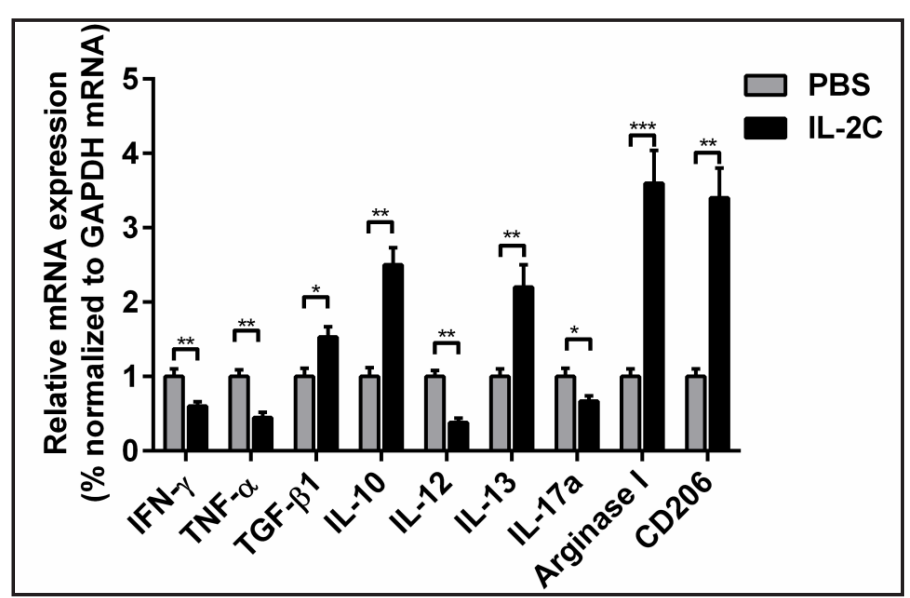

Fig. 8. IL-2C attenuates cardiac pro-inflammatory mediators after I/R injury. Analysis of TNF- $\alpha$, IFN- $\gamma$, IL-12, IL-17A, TGF- $\beta 1$, IL-10, IL-13, Arginase 1, and CD206 mRNA in cardiac tissue was performed by RT-PCR. Data presented were normalized to GAPDH. groups on day 1 (Fig. 11A).

Surprisingly, cardiac function in the IL-2C group was slightly improved on day 5 , although this trend did not reach statistical significance (Fig. 11B). In parallel, we observed reduction of pro-inflammatory mediators after IL-2C treatment (Fig. 11C) and significant reduction of myocardial fibrosis on day 14 (Fig. 11D).

\section{Discussion}

Previous studies in our laboratory demonstrated that the adoptive transfer of in vitroactivated Tregs suppressed MIRI, whereas freshly isolated Tregs had no effect [32]. However, adoptive transfer therapy using Tregs is limited by inadequate purity of isolated Treg cell populations, insufficient numbers for transfer, and potential instability [33]. In this study, we demonstrate an alternative to adoptive transfer using selective in vivo expansion of Treg numbers. Low doses of IL-2 complexed with an anti-IL-2 neutralizing antibody (JES6-1) (IL-2C) induced a sustained increase in both systemic and cardiac Tregs. Our data also demonstrate that IL-2C therapy can be used to attenuate MIRI by selectively expanding in 
Fig. 9. Treg depletion abolished the protection of IL-2C on I/R injury. A. Representative images of CD $4{ }^{+} \mathrm{CD} 25^{+} \mathrm{Foxp}^{+}$ $\mathrm{T}$ cells attained by FACS in the IL-2C group and IL-2C/ PC61 group are shown. The numbers in upper right quadrants indicate percentages of these cells. B. Representative images of $\mathrm{LV}$ slices and quantification of infarct size of myocardium from IL-2C and IL2C/PC61 groups 4 hours after I/R. C. Representative Mmode images of $\mathrm{LV}$, ejection fraction and LV fractional shortening from IL2C and IL-2C/PC61 groups 1 day after I/R. Data are shown as the mean $\pm \mathrm{SD}$ of 3 to 6 independ-
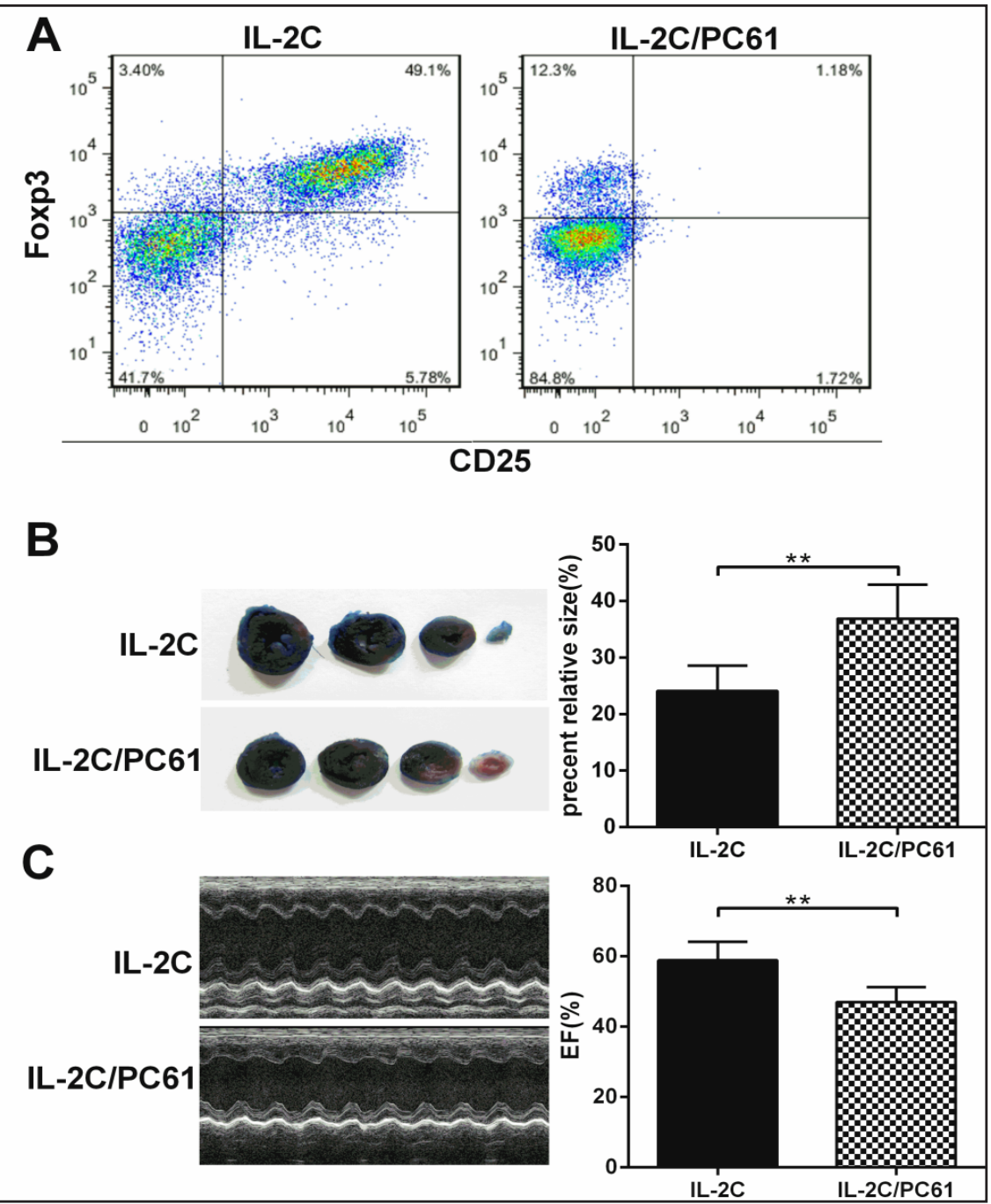

ent experiments.

${ }^{\#} \mathrm{P}>0.05,{ }^{*} \mathrm{P}<0.05,{ }^{* *} \mathrm{P}<0.01,{ }^{* * *} \mathrm{P}<0.001$, and ${ }^{* * * *} \mathrm{P}<0.0001$.

vivo CD4+CD25+Foxp3+ Tregs, which could be reversed through CD25+ Treg depletion. In contrast, TGF- $\beta 1$ and IL-10 neutralization did not affect IL-2C-induced amelioration of MIRI.

Ischaemia-reperfusion triggers a vigorous inflammatory response, augmented by the generation and release of various cytokines, chemokines, and adhesion molecules, which ultimately exacerbate tissue injury [34]. Recently, the pathogenic function of Th1 cells in MIRI was convincingly demonstrated using murine systems [35]. Additional evidence suggests that Th17 cells and interleukin (IL)-17, which are related to autoimmune diseases, may play an important role in MIRI [4]. In contrast, other studies have demonstrated that CD4+CD25+Foxp3+ Tregs exert a protective effect against pathology [32].

We first observed that activated Treg cells appear in response to MIRI, consistent with previous reports that Treg cells are detected in heart tissue with MIRI [32]. In addition, we observed a rapid infiltration of Tregs in heart draining lymph nodes, beginning at 3 days and peaking at 7 days post-reperfusion, suggesting specific recruitment of Tregs from the peripheral blood to the infarct, and from the heart to immune organs, which is driven by MIRI.

IL-2 plays a critical role in regulating homeostasis of Tregs [36]. We found that IL-2C induced sustained increases in Treg numbers in heart and spleen after MIRI. Although the 

tralization did not affect the protection of IL-2C on I/R injury. A. Representative images of LV slices and quantification of myocardium infarct size from different groups 4 hours after I/R. B. Representative M-mode images of LV, ejection fraction and LV fractional shortening from different groups 1 day after I/R. The data are shown as mean \pm SD of 3 to 6 independent experiments. ${ }^{\#} \mathrm{P}>0.05,{ }^{*} \mathrm{P}<0.05,{ }^{* *} \mathrm{P}<0.01$, $* * * \mathrm{P}<0.001$, and $* * * * \mathrm{P}<0.0001$.
Fig. 10. TGF- $\beta 1$ and IL-10 neu-

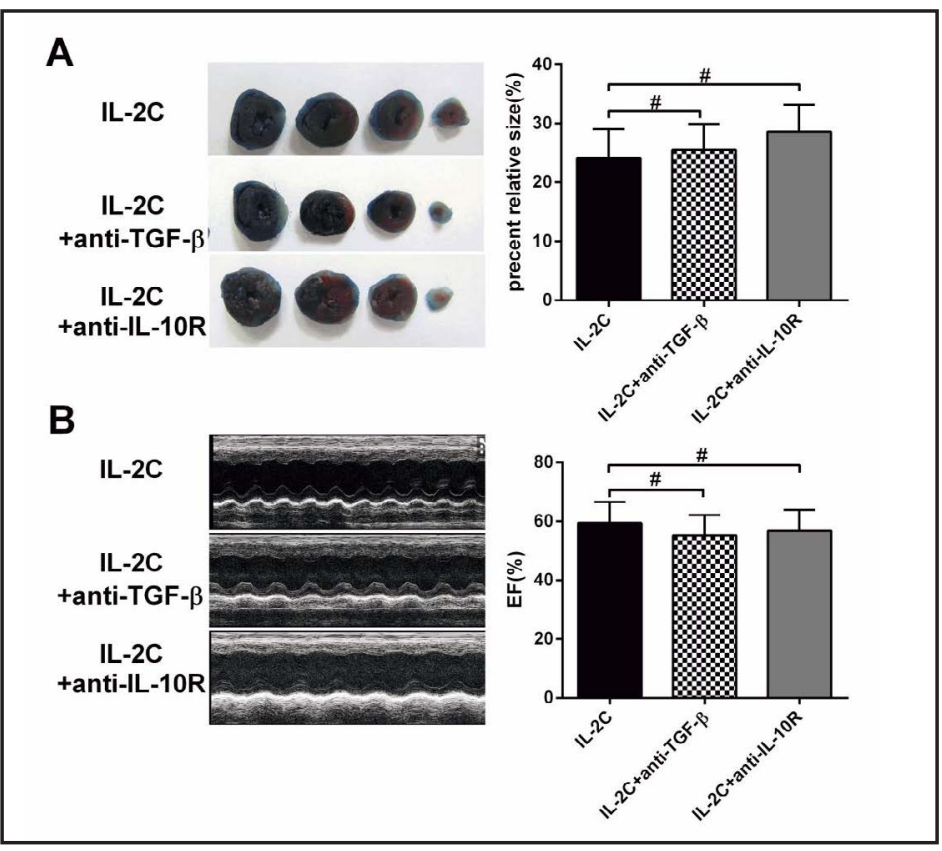

Fig. 11. IL-2C treatment after MIRI attenuates myocardial fibrosis and improves cardiac function, but not infarcted area. A. Representative images of LV slices and quantification of myocardium infarct size from different groups 5 days after I/R. B. M-mode images of LV, ejection fraction, LV fractional shortening, and cardiac pro-inflammatory mediators (C) after IR injury. D. Masson staining in cardiac tissue of different groups. Data are shown as mean \pm SD of 3 to 6 independent experiments. "P $>0.05$, $* \mathrm{P}<0.05, \quad * * \mathrm{P}<0.01, \quad * * * \mathrm{P}<0.001$, and ${ }^{* * * *} \mathrm{P}<0.0001$.

dosing regimen was highly effective in elevating Treg numbers, the mechanisms by which the IL-2/anti-IL-2 $\mathrm{mAb}$ complex stimulates expansion of Tregs has not yet been fully defined. Sustained selective expansion of Tregs in lymphoid compartments and increased Treg numbers in cardiac tissue in response to IL-2C treatment resulted in suppressed IR injury and improved cardiac function.
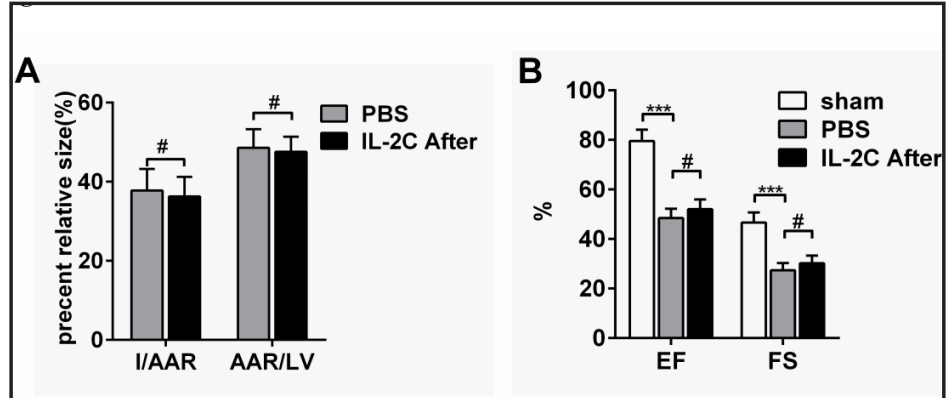

C
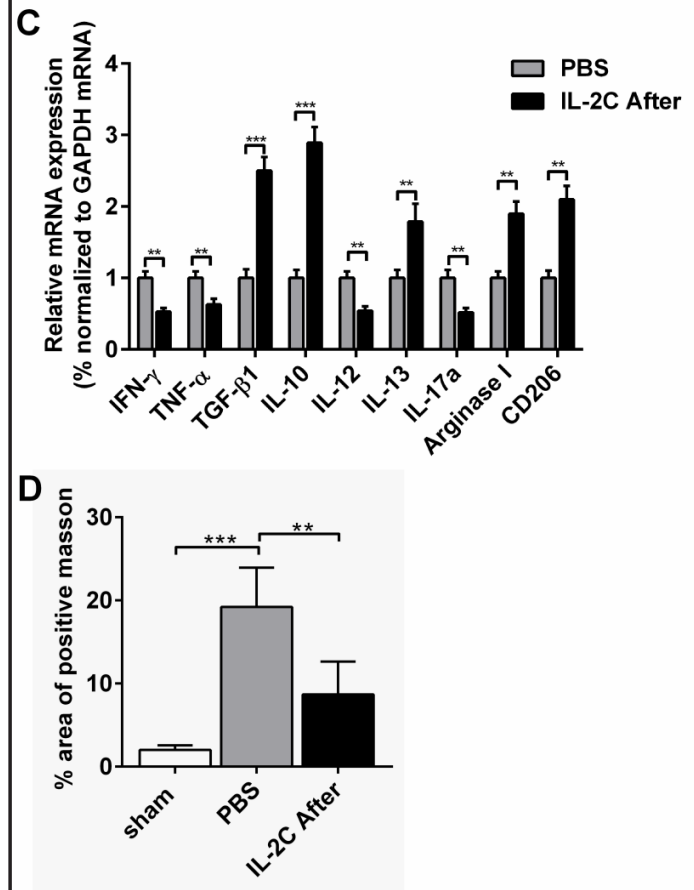
The mechanisms underlying the suppressive effects of Tregs in vivo appear to be complex. Apoptosis has been proposed as an important mechanism for cell death in reperfused ischaemic myocardium [31]. This mechanism could be regulated by oxygen free radicals, cytokines such as TNF- $\alpha$ and IL-6, and neutrophil accumulation [37]. A previous study in our laboratory illustrated that Tregs can directly protect neonatal rat cardiomyocytes from LPS-induced apoptosis, and this protection is dependent on cell-cell contact and IL-10 expression, resulting in ameliorated cardiac remodelling [13]. From our collective results, which demonstrate that IL-2C significantly attenuated cardiomyocyte apoptosis after IR injury, we infer that inhibition of apoptosis was the major mechanism for Treg-exerted protection from IR injury. The Bcl-2 family consists of pro- and anti-apoptotic members, and the balance between pro- and anti-apoptotic proteins determines whether cells survive or undergo apoptosis after a stimulus or injury. Our in vivo results show that IL-2C downregulates caspase- 3 activity and the ratio of pro-apoptotic (Bax) to anti-apoptotic (Bcl-2) proteins. To further explore this finding, we used PC/61 to deplete CD25+ Tregs. Our data demonstrated that Treg depletion resulted in increased infarct size, myocardial injury, and cardiac dysfunction.

IL-10 and TGF- $\beta 1$ are key mediators of Tregs during pathology [8], illustrated well within the tumour and inflammation microenvironment [38-40]. Moreover, previous reports have demonstrated that both of these factors showed protective effects in MIRI [41, 42]. We observed increased levels of IL-10 and TGF- $\beta 1$ in infarcted hearts after IL-2C treatment. We infer that infiltrated Treg cells are the source of increased IL-10 and TGF- $\beta 1$. Surprisingly, anti-IL-10R or anti-TGF- $\beta 1$ Abs did not cancel the protective effect on MIRI, although observed effects were somewhat milder than that seen in control Tregs. Taken together, these data suggest that IL-2C-mediated cardiac protection against Tregs might not be dependent on a single mechanism of suppression. Both CD4+ Th1- and Th17-derived cytokines, including IFN- $\gamma$ and IL-17, contribute to the development of MIRI [4, 35]. In this study, IL-2C therapy effectively prevented IFN- $\gamma$, IL-12, TNF- $\alpha$ and IL-17 secretion in infarcted heart, indicating that Treg expansion induced by IL-2C suppresses the ability of Th1 and Th17 cells to secrete cytokines, which is another important mechanism for Treg function.

Neutrophil recruitment plays a major role in myocardial damage after I/R [43]. We showed that Tregs restrict the infiltration of neutrophils. Previously, depletion of IL-17A was shown to inhibit neutrophil infiltration in the heart after IR [4], so we infer that downregulation of IL-17A here partially contributes to the observed decrease in neutrophils.

Treg cells have also been reported to affect the differentiation of macrophages. Liu et al.'s [44] research showed that Treg cells promote the differentiation of M2 anti-inflammatory macrophages and inhibited M1 pro-inflammatory macrophages. M2-like macrophages activated by Tregs have well known anti-inflammatory characteristics and are an integral component of the wound-healing processes [45]. Consistently, experimental modulation of macrophage polarization towards an M2 state has been previously demonstrated to improve wound healing post-IR [46]. Alternative macrophage activation is initiated in response to IL10 or TGF- $\beta$. We show here that IL-10, TGF- $\beta 1$, IL-13, Arginase 1 and CD206 were significantly increased in heart tissue after IL-2C treatment, indicating M2-like macrophage differentiation. Production of IL-10 and TGF- $\beta 1$ by M2-like cells themselves might have further contributed to the M2-containing milieu in situ. However, we cannot exclude Treg cell-mediated contactdependent mechanisms that may also contribute to monocyte/macrophage polarization. In addition, cardiac fibrosis was also significantly increased on day 28 after IL-2C treatment in the IR model, suggesting that IL-2C contributes to improved cardiac healing. Previous reports demonstrate that IL-13, which was strongly induced by CD28-SA treatment, synergizes with TGF- $\beta 1$ to promote collagen synthesis in myofibroblasts [45]. These results indicate that the differentiation of M2 by Tregs could be partially responsible for improved healing observed after MIRI in the IL-2C-treated group.

The majority of previous experimental studies on post-MI healing have demonstrated that Tregs play a protective role in this process $[13,19,32,45]$. However, Mathes et al. found

\section{KARGER}


that endogenous and MHC-II non-restricted Foxp3+ T-cells could drive MIRI [47]. From this, we infer the following: 1) these endogenous and MHC-II non-restricted Foxp3+ T-cells were inflammatory, and their inhibitory ability and expression of inflammation mediators, such as IFN- $\gamma$, IL-10, and TGF- $\beta 1$, were unknown; and 2) the overactive inflammation observed three days after MIRI help convert conventional Foxp3+ T-cells to IFN- $\gamma+$ Foxp3+ T-cells. In contrast, Tregs expanded by IL-2C produce a large amounts of IL-10 and TGF- $\beta 1$ in our study, exerting powerful inhibitory effects on MIRI.

\section{Conclusion}

Treatment with IL-2C attenuates MIRI and improves cardiac recovery after MIRI by expanding Tregs, decreasing myocardial apoptosis and infiltration of inflammatory cells, and increasing M2 and associated anti-inflammatory factors, all of which are dependent on CD25+ Tregs but neither IL-10 nor TGF- $\beta 1$. Considering its convenience of manipulation and safety, IL-2C is a promising candidate for clinical application in MIRI.

\section{Abbreviations}

IL-2C (IL-2/anti-IL-2 complex); Tregs (Regulatory T cells); MIRI (myocardial ischaemia/ reperfusion (I/R) injury).

\section{Acknowledgements}

This work was supported by grants from National Natural Science Foundations of China (NO. 81270354 and NO. 81470420 to Dr. Q.T.Z).

\section{Disclosure Statement}

None of the authors had a conflict of interest.

\section{References}

1 Yellon DM, Hausenloy DJ: Myocardial reperfusion injury. N Engl J Med 2007;357:1121-1135.

-2 Timmers L, Pasterkamp G, de Hoog VC, Arslan F, Appelman Y, de Kleijn DP: The innate immune response in reperfused myocardium. Cardiovasc Res 2012;94:276-283.

- Y Yang Z, Day YJ, Toufektsian MC, Xu Y, Ramos SI, Marshall MA, French BA, Linden J: Myocardial InfarctSparing Effect of Adenosine A2A Receptor Activation is due to its Action on CD4+ T Lymphocytes. Circulation 2006;114:2056-2064.

- Liao YH, Xia N, Zhou SF, Tang TT, Yan XX, Lv BJ, Nie SF, Wang J, Iwakura Y, Xiao H, Yuan J, Jevallee H, Wei F, Shi GP, Cheng X: Interleukin-17A contributes to myocardial ischemia/reperfusion injury by regulating cardiomyocyte apoptosis and neutrophil infiltration. J Am Coll Cardiol 2012;59:420-429.

5 Sakaguchi S, Ono M, Setoguchi R, Yagi H, Hori S, Fehervari Z, Shimizu J, Takahashi T, Nomura T: Foxp3+ CD25+ CD4+ natural regulatory $\mathrm{T}$ cells in dominant self-tolerance and autoimmune disease. Immunol Rev 2006;212:8-27.

6 Mahajan D, Wang Y, Qin X, Wang Y, Zheng G, Wang YM, Alexander SI, Harris DC: CD4+CD25+ regulatory $\mathrm{T}$ cells protect against injury in an innate murine model of chronic kidney disease. J Am Soc Nephrol 2006;17:2731-2741.

7 Lewkowicz P, Lewkowicz N, Sasiak A, Tchorzewski H: Lipopolysaccharide-activated CD4+CD25+ T regulatory cells inhibit neutrophil function and promote their apoptosis and death. J Immunol 2006;177:7155-7163.

-8 Vignali DA, Collison LW, Workman CJ: How regulatory T cells work. Nat Rev Immunol 2008;8:523-532.

-9 Kinsey GR, Sharma R, Huang L, Li L, Vergis AL, Ye H, Ju ST, Okusa MD: Regulatory T cells suppress innate immunity in kidney ischemia-reperfusion injury. J Am Soc Nephrol 2009;20:1744-1753. 


\section{Cellular Physiology Cell Physiol Biochem 2017;44:1810-1827 \begin{tabular}{l|l|l}
\hline and BOI: 10.1159/000485818 & $\begin{array}{l}\text { C } 2017 \text { The Author(s). Published by S. Karger AG, Basel } \\
\text { www.karger.com/cpb }\end{array}$ \\
\hline
\end{tabular}}

10 Kinsey GR, Huang L, Jaworska K, Khutsishvili K, Becker DA, Ye H, Lobo PI, Okusa MD: Autocrine adenosine signaling promotes regulatory T cell-mediated renal protection. J Am Soc Nephrol 2012;23:1528-1537.

11 Lu L, Li G, Rao J, Pu L, Yu Y, Wang X, Zhang F: In vitro induced CD4(+)CD25(+)Foxp3(+) Tregs attenuate hepatic ischemia-reperfusion injury. Int Immunopharmacol 2009;9:549-552.

12 Li P, Gan Y, Sun BL, Zhang F, Lu B, Gao Y, Liang W, Thomson AW, Chen J, Hu X: Adoptive regulatory T-cell therapy protects against cerebral ischemia. Ann Neurol 2013;74:458-471.

-13 Tang TT, Yuan J, Zhu ZF, Zhang WC, Xiao H, Xia N, Yan XX, Nie SF, Liu J, Zhou SF, Li JJ, Yao R, Liao MY, Tu X, Liao YH, Cheng X: Regulatory T cells ameliorate cardiac remodeling after myocardial infarction. Basic Res Cardiol 2012;107:232.

14 Gaffen SL, Liu KD: Overview of interleukin-2 function, production and clinical applications. Cytokine 2004;28:109-123.

15 Finkelman FD, Madden KB, Morris SC, Holmes JM, Boiani N, Katona IM, Maliszewski CR: Anti-cytokine antibodies as carrier proteins. Prolongation of in vivo effects of exogenous cytokines by injection of cytokine-anti-cytokine antibody complexes. J Immunol 1993;151:1235-1244.

16 Webster KE, Walters S, Kohler RE, Mrkvan T, Boyman O, Surh CD, Grey ST, Sprent J: In vivo expansion of $\mathrm{T}$ reg cells with IL-2-mAb complexes: Induction of resistance to EAE and long-term acceptance of islet allografts without immunosuppression. J Exp Med 2009;206:751-760.

17 Dinh TN, Kyaw TS, Kanellakis P, To K, Tipping P, Toh BH, Bobik A, Agrotis A: Cytokine therapy with interleukin-2/anti-interleukin-2 monoclonal antibody complexes expands CD4+CD25+Foxp3+ regulatory $\mathrm{T}$ cells and attenuates development and progression of atherosclerosis. Circulation 2012;126:1256-1266.

18 Majeed B, Tawinwung S, Eberson LS, Secomb TW, Larmonier N, Larson DF: Interleukin-2/Anti-Interleukin-2 immune complex expands regulatory t cells and reduces angiotensin II-Induced aortic stiffening. Int J Hypertens 2014;2014:126365.

19 Zeng Z, Yu K, Chen L, Li W, Xiao H, Huang Z: Interleukin-2/Anti-Interleukin-2 immune complex attenuates cardiac remodeling after myocardial infarction through expansion of regulatory t cells. J Immunol Res 2016;2016:8493767.

20 Tarnavski O, McMullen JR, Schinke M, Nie Q, Kong S, Izumo S: Mouse cardiac surgery: Comprehensive techniques for the generation of mouse models of human diseases and their application for genomic studies. Physiol Genomics 2004;16:349-360.

21 Wang Y, Gao E, Tao L, Lau WB, Yuan Y, Goldstein BJ, Lopez BL, Christopher TA, Tian R, Koch W, Ma XL: AMPactivated protein kinase deficiency enhances myocardial ischemia/reperfusion injury but has minimal effect on the antioxidant/antinitrative protection of adiponectin. Circulation 2009;119:835-844.

22 Most P, Seifert H, Gao E, Funakoshi H, Volkers M, Heierhorst J, Remppis A, Pleger ST, DeGeorge BJ, Eckhart AD, Feldman AM, Koch WJ: Cardiac S100A1 protein levels determine contractile performance and propensity toward heart failure after myocardial infarction. Circulation 2006;114:1258-1268.

23 Li Y, Garson CD, Xu Y, Beyers RJ, Epstein FH, French BA, Hossack JA: Quantification and MRI validation of regional contractile dysfunction in mice post myocardial infarction using high resolution ultrasound. Ultrasound Med Biol 2007;33:894-904.

-24 Shibata R, Sato K, Pimentel DR, Takemura Y, Kihara S, Ohashi K, Funahashi T, Ouchi N, Walsh K: Adiponectin protects against myocardial ischemia-reperfusion injury through AMPK- and COX-2-dependent mechanisms. Nat Med 2005;11:1096-1103.

-25 Metzler B, Mair J, Lercher A, Schaber C, Hintringer F, Pachinger O, Xu Q: Mouse model of myocardial remodelling after ischemia: Role of intercellular adhesion molecule-1 Cardiovasc Res 2001;49:399407.

26 Haubner BJ, Neely GG, Voelkl JG, Damilano F, Kuba K, Imai Y, Komnenovic V, Mayr A, Pachinger O, Hirsch E, Penninger JM, Metzler B: PI3Kgamma protects from myocardial ischemia and reperfusion injury through a kinase-independent pathway. PloS One 2010;5:e9350.

27 Brinks H, Boucher M, Gao E, Chuprun JK, Pesant S, Raake PW, Huang ZM, Wang X, Qiu G, Gumpert A, Harris DM, Eckhart AD, Most P, Koch WJ: Level of G protein-coupled receptor kinase-2 determines myocardial ischemia/reperfusion injury via pro- and anti-apoptotic mechanisms. Circ Res 2010;107:1140-1149.

-28 La Cava A, Van Kaer L, Fu-Dong-Shi: CD4+CD25+ Tregs and NKT cells: Regulators regulating regulators. Trends Immunol 2006;27:322-327. 


\section{Cellular Physiology Cell Physiol Biochem 2017;44:1810-1827 \begin{tabular}{l|l|l}
\hline and Biochemistry 10.1159/000485818 & $\begin{array}{l}\text { C) } 2017 \text { The Author(s). Published by S. Karger AG, Basel } \\
\text { www.karger.com/cpb }\end{array}$ \\
\hline
\end{tabular}}

Xiao et al.: IL-2/Anti-IL-2 mAb and MIRI

29 Zigmond E, Preston S, Pappo O, Lalazar G, Margalit M, Shalev Z, Zolotarov L, Friedman D, Alper R, Ilan Y: Beta-glucosylceramide: A novel method for enhancement of natural killer T lymphoycte plasticity in murine models of immune-mediated disorders. Gut 2007;56:82-89.

-30 Kim HJ, Hwang SJ, Kim BK, Jung KC, Chung DH: NKT cells play critical roles in the induction of oral tolerance by inducing regulatory $\mathrm{T}$ cells producing IL-10 and transforming growth factor beta, and by clonally deleting antigen-specific T cells. Immunology 2006;118:101-111.

-31 Hamacher-Brady A, Brady NR, Gottlieb RA: The interplay between pro-death and pro-survival signaling pathways in myocardial ischemia/reperfusion injury: Apoptosis meets autophagy. Cardiovasc Drugs Ther 2006;20:445-462.

-32 Xia N, Jiao J, Tang TT, Lv BJ, Lu YZ, Wang KJ, Zhu ZF, Mao XB, Nie SF, Wang Q, Tu X, Xiao H, Liao YH, Shi GP, Cheng X: Activated regulatory T-cells attenuate myocardial ischaemia/reperfusion injury through a CD39dependent mechanism. Clin Sci (Lond) 2015;128:679-693.

33 Riley JL, June CH, Blazar BR: Human T regulatory cell therapy: Take a billion or so and call me in the morning. Immunity 2009;30:656-665.

34 Steffens S, Montecucco F, Mach F: The inflammatory response as a target to reduce myocardial ischaemia and reperfusion injury. Thromb Haemost 2009;102:240-247.

-35 Zhao G, Wang S, Wang Z, Sun A, Yang X, Qiu Z, Wu C, Zhang W, Li H, Zhang Y, Zhao J, Zou Y, Ge J: CXCR6 deficiency ameliorated myocardial ischemia/reperfusion injury by inhibiting infiltration of monocytes and IFN-gamma-dependent autophagy. Int J Cardiol 2013;168:853-862.

36 Setoguchi R, Hori S, Takahashi T, Sakaguchi S: Homeostatic maintenance of natural Foxp3(+) CD25(+) CD4 (+) regulatory T cells by interleukin (IL)-2 and induction of autoimmune disease by IL-2 neutralization. J Exp Med 2005;201:723-735.

37 Nakamura M, Wang NP, Zhao ZQ, Wilcox JN, Thourani V, Guyton RA, Vinten-Johansen J: Preconditioning decreases Bax expression, PMN accumulation and apoptosis in reperfused rat heart. Cardiovasc Res 2000;45:661-670.

38 Wang Y, Liu T, Tang W, Deng B, Chen Y, Zhu J, Shen X: Hepatocellular carcinoma cells induce regulatory t cells and lead to poor prognosis via production of transforming growth factor-beta1 Cell Physiol Biochem 2016;38:306-318.

-39 Seiffart V, Zoeller J, Klopfleisch R, Wadwa M, Hansen W, Buer J, Riedel C, Westendorf AM: IL10-Deficiency in CD4(+) t cells exacerbates the IFNgamma and IL17 response during bacteria induced colitis. Cell Physiol Biochem 2015;36:1259-1273.

40 Shen Y, Wei Y, Wang Z, Jing Y, He H, Yuan J, Li R, Zhao Q Wei L, Yang T, Lu J: TGF-beta regulates hepatocellular carcinoma progression by inducing Treg cell polarization. Cell Physiol Biochem 2015;35:1623-1632.

41 Yang Z, Zingarelli B, Szabo C: Crucial role of endogenous interleukin-10 production in myocardial ischemia/ reperfusion injury. CIrculation 2000;101:1019-1026.

42 Baxter GF, Mocanu MM, Brar BK, Latchman DS, Yellon DM: Cardioprotective effects of transforming growth factor-beta1 during early reoxygenation or reperfusion are mediated by p42/p44 MAPK. J Cardiovasc Pharmacol 2001;38:930-939.

-43 Wu C, Yosef N, Thalhamer T, Zhu C, Xiao S, Kishi Y, Regev A, Kuchroo VK: Induction of pathogenic TH17 cells by inducible salt-sensing kinase SGK1. Nature 2013;496:513-517.

44 Liu G, Ma H, Qiu L, Li L, Cao Y, Ma J, Zhao Y: Phenotypic and functional switch of macrophages induced by regulatory CD4+CD25+ T cells in mice. Immunol Cell Biol 2011;89:130-142.

-45 Weirather J, Hofmann UD, Beyersdorf N, Ramos GC, Vogel B, Frey A, Ertl G, Kerkau T, Frantz S: Foxp3+ CD4+ $\mathrm{T}$ cells improve healing after myocardial infarction by modulating monocyte/macrophage differentiation. Circ Res 2014;115:55-67.

-46 Tian Y, Piras BA, Kron IL, French BA, Yang Z: Adenosine 2B receptor activation reduces myocardial reperfusion injury by promoting Anti-Inflammatory macrophages differentiation via PI3K/Akt pathway. Oxid Med Cell Longev 2015;2015:585297.

47 Mathes D, Weirather J, Nordbeck P, Arias-Loza AP, Burkard M, Pachel C, Kerkau T, Beyersdorf N, Frantz S, Hofmann U: CD4+ Foxp3+ T-cells contribute to myocardial ischemia-reperfusion injury. J Mol Cell Cardiol 2016;101:99-105. 